TAXONOMY AND NOMENCLATURE

\title{
A new species of Trileptium (Nematoda: Thoracostomopsidae) from Bahia, Brazil
}

\author{
Ana C. Vilas-Boas ${ }^{1 *}$, Maria C. da Silva², Orane F. de Souza Alves ${ }^{1}$, \\ Francisco J.V. de Castro² \& Eraldo P. Pinheiro-Junior ${ }^{1}$
}

\author{
${ }^{1}$ Museu de História Natural da Bahia, Universidade Federal da Bahia. Rua Barão de Geremoabo, 40170-290 Salva- \\ dor, BA, Brazil. \\ ${ }^{2}$ Centro de Educação e Saúde, Universidade Federal de Campina Grande. Olho d'água da Bica, 58175-000 Cuité, \\ PB, Brazil. \\ *Corresponding Author E-mail: ananinanina@hotmail.com
}

\begin{abstract}
A new species of a free-living marine nematode found in Brazil is described: Trileptium ribeirensis sp. nov. The type material is deposited in the Nematoda collection of the Museu de História Natural da Bahia, located at the Universidade Federal da Bahia. Trileptium includes eleven valid species of nematodes that have teeth and jaws positioned forward. The species was collected with the help of corers $(3.5 \mathrm{~cm}$ in diameter and $30 \mathrm{~cm}$ long) on a sandy beach in Bahia. This species is distinguished from its congeners based on a combination of characters of the male (cuticle, buccal cavity, supplement and gubernaculum). An updated taxonomic key to the genus is presented.
\end{abstract}

KEY WORDS. Nematode, Salvador, sandy beach, Trileptiinae.

Enoplida are aquatic free-living nematodes, most of which occur in marine environments. LORENZEN (1994) considered this order as monophyletic in view of the presence of metanemes. However, molecular analysis did not corroborate the monophyly of Enoplida (SMol \& Coomans 2006). Enoplida is currently subdivided into seven suborders: Enoplina Chitwood \& Chitwood, 1937; Trefusiina Siddiqi, 1983; Oncholaimina De Ley \& Blaxter, 2002; Ironina Siddiqi, 1983; Tripyloidina De Coninck, 1965; Campydorina Jairajpuri, 1983; and Alaimina Clark, 1961. Enoplina comprises only the superfamily Enoploidea Dujardin, 1845, in which Thoracostomopsidae Filipjev, 1927, is placed. LorENZEN (1994) and Smol \& Coomans (2006) stated that Enoploidea includes the families Enoplidae Dujardin, 1845; Anoplostomatidae Gerlach \& Riemann, 1974; Phanodermatidae Filipjev, 1927; and Anticomidae Filipjev, 1918, in addition to Thoracostomopsidae. However, BIK et al. (2010) showed that the group is paraphyletic, based on morphological and molecular analyses, and proposed the inclusion of Leptosomatidae Filipjev, 1916 (Ironoidea de Man, 1876) in the clade formed by these five families.

Thoracostomopsidae consists of marine and freshwater animals (Enoplolaiminae). These marine species can be found on beaches with intensive hydrodynamics and shallow sublittoral areas, and their abundances vary seasonally (GREENSLADE \& Nicholas 1991, Nicholas 2007). This family forms a monophyletic clade with Enoplidae and Phanodermatidae (BIK et al. 2010).
Thoracostomopsidae consists of three subfamilies: Thoracostomopsinae Filipjev, 1927 (1 genus - Thoracostomopsis Ditlevsen, 1918); Trileptiinae Gerlach \& Riemann, 1974 (1 genus - Trileptium Cobb, 1933); and Enoplolaiminae De Coninck, 1965 (18 genera) (Lorenzen 1981, Nicholas 2007, Lo Russo et al. 2013). The main distinguishing characteristic in this family is the oral cavity, which can be large or small, with or without jaws, with teeth or spear. The presence of cervical setae and the length of the spicules are also diagnostic characters among genera (SMOL \& CoOMANs 2006).

Trileptium was originally mentioned as Trilepta by Совв (1920), when he described the type species, Trilepta guttata. Совв (1933) renamed the genus to Trileptium. It consists of marine nematodes that have teeth and jaws positioned forward, though it is occasionally difficult to see the jaws (PLATT \& WARWICK 1983). Currently, this genus has 11 valid species, with records on the coast of subtidal tropical and temperate countries. VeNEKEY et al. (2010) reported only two species of Trileptium in Brazil: T. stylum Gerlach, 1956, and T. subterraneum (Gerlach, 1952).

\section{MATERIAL AND METHODS}

Ribeira beach is located on the Itapagipe Peninsula $\left(12^{\circ} 55^{\prime} \mathrm{S}, 38^{\circ} 30^{\prime} \mathrm{W}\right)$, east coast of Todos os Santos Bay (TSb), west coast of Salvador, state of Bahia, Brazilian northeast (Fig. 1). This area has been greatly impacted by human activities, such 


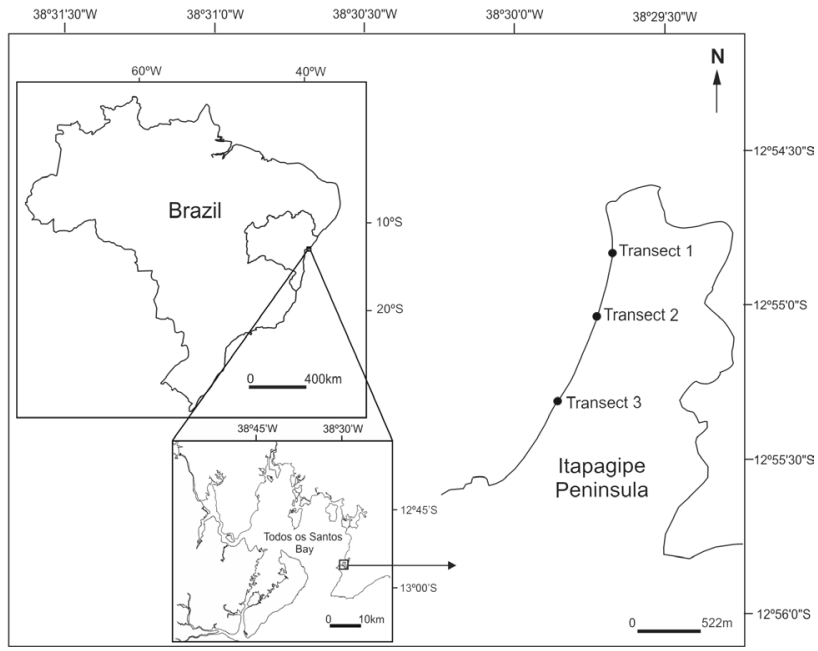

Figure 1. Study area and transects location on Ribeira beach (Bahia, Brazil).

as recreational and construction of habitations and commercial facilities. It consists of a low-energy wave coastline (less than $0.5 \mathrm{~m}$ height), dispersed to a distant part of the coast, and with the absence of rip currents (SiLVA et al. 2010).

The beach sediment is characterized by quartz grains and fragments of carbonate skeletons of marine organisms', and mostly medium-sized sand grains (VILAS BOAS \& BITTENCOURT 1992). The lack of fine fraction is due to turbulence, which conveys the material up to $0.25 \mathrm{~mm}$ in diameter. The slope ranges from 5 to 10 degrees, and the width varies from $20 \mathrm{~m}$ to $35 \mathrm{~m}$ at low tide (Silva et al. 2010).

Nematode sampling was conducted in February, 2009, during a dry period with low spring tide. Samples were taken using corers of $3.5 \mathrm{~cm}$ in diameter and $30 \mathrm{~cm}$ long, divided into three strata: 0-10, 10-20, and 20-30 cm related to sediment depth. They were traced in three transects perpendicular to the waterline in the intertidal zone, with three points representing upper, middle and lower regions. Samples were fixed in saline buffered formalin (10\%) and rinsed by hand in elutriation sieves with $0.5 \mathrm{~mm}$ and $0.045 \mathrm{~mm}$. Nematodes were diaphanized using glycerol-ethanol solutions, according to the DE GRISSE (1969) protocol, and arranged on slides, following the method by Совв (1917).

The description and drawings of the animals were performed under an Olympus optical microscope (CX31), with attached drawing tube. The morphometry was performed using images taken by camera model QImaging Go-3, using the Q Capture software. All measurements are expressed in micrometers $(\mu \mathrm{m})$. Images were imported into the Image-Pro Insight software for analysis. Photographs of the animals were taken under an Olympus microscope (BX53) with DIC.

Animals are deposited in the Nematode collection of the Museum of Zoology, a unit of the Museu de História Natural da Bahia (MHNBA), located at the Universidade Federal da Bahia. The institution is recognized by the Brazilian Ministry of Environment.

\section{TAXONOMY}

\author{
Phylum Nematoda Potts, 1932 \\ Order Enoplida Filipjev, 1929
}

Suborder Enoplina Chitwood \& Chitwood, 1937

Enoploidea Dujardin, 1845

\section{Thoracostomopsidae Filipjev, 1927 (adapted \\ from LoRenZen 1994, SMOL \& CoOMANs 2006, NiCHOLAS 2007)}

Diagnosis. Presence of three prominent lips. Setiform inner labial setae (papilliform only in Fenestrolaimus), whereas the outer labial and cephalic setae are robust and long. Cephalic organs are usually present, situated frontally or ventrofrontally in relation to the lateral cephalic setae exhibiting a variable form. Non-spiral and small amphidial fovea located posterior to the cephalic capsule are most likely absent. The inner layer of the cuticle forms a cephalic capsule, and the pharyngeal muscles are attached to it. Conical buccal cavity is tapered with three jaws and three conical teeth associated with the base of the jaws (one dorsal and two ventrosublateral) or a long eversible spear in Thoracostomopsinae members. Only dorsolateral orthometanemes with a robust scapulus occur but without caudal filament. The endings of the epidermal glands are particularly well differentiated. Female reproductive system is didelphic-amphidelfic, with antidromously reflexed ovaries. Caudal glands can be found in the pre-caudal region.

\section{Trileptium Cobb, 1933 (adapted from PLATT \& WARWICK 1983, Nicholas 2007)}

Type species. Trileptium guttatum (Cobb, 1920).

Diagnosis. Cuticle may be smooth or slightly striated. Three small lips, one dorsal and two subventral. The cephalic setae are arranged in three circles: six inner labial, six outer labial and four cephalic. Males also have a circle with subcephalic setae. The buccal cavity consists of one or three teeth, with similar sizes, well developed and positioned near the opening of the cavity. Subventral teeth may be located at the same level or more anterior to the dorsal tooth. Underdeveloped jaws may or may not be present. The genus has variable shapes and arrangements of spicules and gubernaculums. A pre-cloacal supplement may be present or absent.

Species included. This genus includes the 11 valid species listed below (modified from NicHOLAs 2007):

Trileptium americanum (Keppner, 1987)

Trileptium australis Nicholas, 2007

Trileptium ayum Inglis, 1964

Trileptium guttatum (Cobb, 1920)

Trileptium iacobinum Wieser, 1959

Trileptium longisetosum Inglis, 1966

Trileptium otti Jensen \& Gerlach, 1976 
Trileptium parisetum Warwick \& Platt, 1973

Trileptium salvadoriense Gerlach, 1955

Trileptium stylum Gerlach, 1956

Trileptium subterraneum (Gerlach, 1952)

\section{Trileptium ribeirensis sp. nov.}

Figs. 2-17, Table 1

urn:Isid:zoobank.org:act:1047B3EC-5851-43A7-96D5-37D49CAF6FB0

Diagnosis. Slightly striated cuticle, visible in the anterior region and through the tail. Three lips. Cephalic arrangement in three rings, outer-labial setae greater than cephalic setae. Males with two pairs of sub-cephalic setae. Narrow buccal cavity with three jaws and three isometric teeth, all on the same level and across the transverse mandibular bar. Males with two opposite testis left to the intestine. Simple shaped spicules. Laminar gubernaculum with a dorsal-caudal apophysis. Tubular pre-cloacal supplement. Conical tail tapering at the terminal portion.

Type material. Holotype (male): Brazil, Bahia: Salvador (Ribeira Beach, $12^{\circ} 55^{\prime} \mathrm{S}, 38^{\circ} 30^{\prime} \mathrm{W}$ ), $10-20 \mathrm{~cm}$ depth, collected with a corer, middle region, coarse sand, $45 \mu \mathrm{m}$ sieve), 11.II.2009, Alves, O.F.S. et al. leg., Museu de História Natural da Bahia, Brazil (UFBA NEM01063). Allotype (female): Brazil, Bahia: Salvador (Ribeira Beach, $12^{\circ} 55^{\prime} \mathrm{S}, 38^{\circ} 30^{\prime} \mathrm{W}, 0-10 \mathrm{~cm}$ depth, collected with a corer, middle region, medium sand, $500 \mu \mathrm{m}$ sieve), 09.II.2009, Alves, O.F.S. et al. leg., Museu de História Natural da Bahia, Brazil (UFBA NEM00371). Paratypes: Brazil, Bahia: Salvador (Ribeira Beach, $12^{\circ} 55^{\prime} \mathrm{S}, 38^{\circ} 30^{\prime} \mathrm{W}, 0-30 \mathrm{~cm}$ depth, collected with a corer, middle region, medium sand, 45 and $500 \mu \mathrm{m}$ sieves), 9 males and 4 females, 11.II.2009; Alves, O.F.S. et al. leg., Museu de História Natural da Bahia, Brazil (UFBA NEM00509, UFBA NEM00963, UFBA NEM01036, UFBA NEM01055, UFBA NEM01166, UFBA NEM01171, UFBA NEM01217, UFBA NEM01224, UFBA NEM01351, UFBA NEM01357, UFBA NEM01358, UFBA NEM01366, UFBA NEM01388).

Description. Holotype: Slender and elongated body, particularly in the extremities (Length: $3713 \mu \mathrm{m}$ ). Slightly striated cuticle, visible in the anterior region, even after the nerve ring, and little less in the cloaca region extending through the tail. Narrow head with a sclerotized cephalic capsule. Presence of three lips. Cephalic arrangement in $6+6+4$ : six inner-labial thick and short setae $(6 \mu \mathrm{m})$ and six outer-labial setae $(50 \mu \mathrm{m})$ greater than cephalic setae $(30 \mu \mathrm{m})$. Two pairs of sub-cephalic setae were also observed $(31 \mu \mathrm{m})$. Somatic setae $(13 \mu \mathrm{m})$ up to the nerve ring and absent in the rest of the body. Presence of orthometanemes, with one complete filament with $24 \mu \mathrm{m}$. Narrow buccal cavity with three jaws $(20 \mu \mathrm{m})$ and three isometric teeth $(13 \mu \mathrm{m})$, all on the same level and across the transverse mandibular bar. Pocket-shaped amphidial fovea, near the base of the cephalic capsule, which occupies $17 \%$ of the corresponding body diameter. Circular cephalic ring positioned between the inner labial setae circle and the outer labial setae circle $(1 \mu \mathrm{m}$ from the anterior end). Cylindrical pharynx with crenated contour and without a terminal bulb $(742 \mu \mathrm{m})$. Triangular cardia inserted
Table 1. Males and females measurements $(\mu \mathrm{m})$ of Trileptium ribeirensis sp. nov. (cbd) corresponding body diameter; (V\%) position of vulva as a percentage of body length from the anterior end; (a) body length divided by maximum body diameter; (b) body length divided by pharyngeal length; (c) body length divided by tail length; $\left(c^{\prime}\right)$ tail length divided by body width at the anus or cloacal opening.

\begin{tabular}{|c|c|c|c|c|}
\hline & $\begin{array}{l}\text { Holotype } \\
\text { male }\end{array}$ & $\begin{array}{l}\text { Paratypes } \\
(\text { males }=9)\end{array}$ & $\begin{array}{l}\text { Alotype } \\
\text { female }\end{array}$ & $\begin{array}{c}\text { Paratypes } \\
(\text { females }=4)\end{array}$ \\
\hline Body length & 3713 & $2359-4415$ & 4320 & $3489-4211$ \\
\hline Head length & 20 & $20-25$ & 23 & $21-24$ \\
\hline Head width at cephalic ring & 17 & 14-18 & 15 & $15-20$ \\
\hline Head to cephalic ring distance & 1 & $2-3$ & 2 & $2-3$ \\
\hline Head width at lips & 14 & $12-16$ & 15 & $14-17$ \\
\hline Maximum width at lips & 18 & $16-18$ & 19 & $19-21$ \\
\hline Amphid width & 4 & 4 & 4 & $3-5$ \\
\hline Amphid cbd & 24 & $20-28$ & 25 & $23-30$ \\
\hline Buccal cavity length & 30 & $26-32$ & 34 & $29-34$ \\
\hline Buccal cavity cbd & 19 & $18-21$ & 21 & $19-22$ \\
\hline Onchium length & 13 & $10-12$ & 12 & $10-15$ \\
\hline Jaw length & 20 & $9-13$ & 16 & $13-16$ \\
\hline Cephalic capsule length & 22 & $19-24$ & 23 & $21-25$ \\
\hline Width at base of cephalic capsule & 23 & $22-25$ & 26 & $24-27$ \\
\hline Inner labial setae length & 6 & 4-7 & 6 & 4-6 \\
\hline Outer labial setae length & 50 & 44-51 & 41 & $40-45$ \\
\hline Cephalic setae length & 30 & $16-28$ & 17 & $11-15$ \\
\hline Longest subcephalic setae length & 31 & $23-31$ & - & - \\
\hline Somatic setae length & 13 & $10-14$ & 13 & $10-13$ \\
\hline Head to nerve ring distance & 172 & $154-210$ & 189 & $160-182$ \\
\hline Nerve ring cbd & 44 & $42-53$ & 49 & $46-54$ \\
\hline Pharynx length & 742 & $713-895$ & 782 & $692-766$ \\
\hline Anterior testis length & 138 & $50-143$ & - & - \\
\hline Posterior testis length & 123 & $55-118$ & - & - \\
\hline Anterior ovary length & - & - & 1984 & $771-1360$ \\
\hline Posterior ovary length & - & - & 1990 & $841-1878$ \\
\hline Head to cloaca/anus distance & 3524 & 2161-4192 & 4138 & $3307-4005$ \\
\hline Head to vulva distance & - & - & 2700 & $2296-2710$ \\
\hline Tail length & 189 & $177-223$ & 181 & $178-206$ \\
\hline Spicules, arc length & 56 & $55-62$ & - & - \\
\hline Spicules, chord length & 48 & $47-56$ & - & - \\
\hline Sppineret length & 4 & $3-5$ & 4 & $4-5$ \\
\hline Gubernaculum length & 13 & $9-16$ & - & - \\
\hline Apophysis length & 6 & $4-8$ & - & - \\
\hline Supplement length & 8 & $6-9$ & - & - \\
\hline Supplement to cloaca distance & 38 & $37-48$ & - & - \\
\hline Maximum body width & 46 & 44-56 & 62 & $53-65$ \\
\hline Width at cloaca/anus & 38 & $38-48$ & 46 & $44-52$ \\
\hline Orthometanemes length & 24 & 28-39 & 36 & $24-45$ \\
\hline V\% & - & - & 62.5 & $62.1-66.8$ \\
\hline a & 81.0 & $44.5-86.5$ & 69.6 & $56.8-69.8$ \\
\hline b & 5.0 & $2.7-4.9$ & 5.5 & 4.6-5.5 \\
\hline c & 19.6 & $11.9-21.7$ & 23.8 & $19.1-20.8$ \\
\hline$c^{\prime}$ & 4.9 & $3.7-5.2$ & 4.0 & $3.0-4.0$ \\
\hline
\end{tabular}

in the intestine. No excretory-secretory system was observed. Two opposite testis (anterior $138 \mu \mathrm{m}$, and posterior $123 \mu \mathrm{m}$ ) left to the intestine. Simple shaped spicules lacking capitulum 

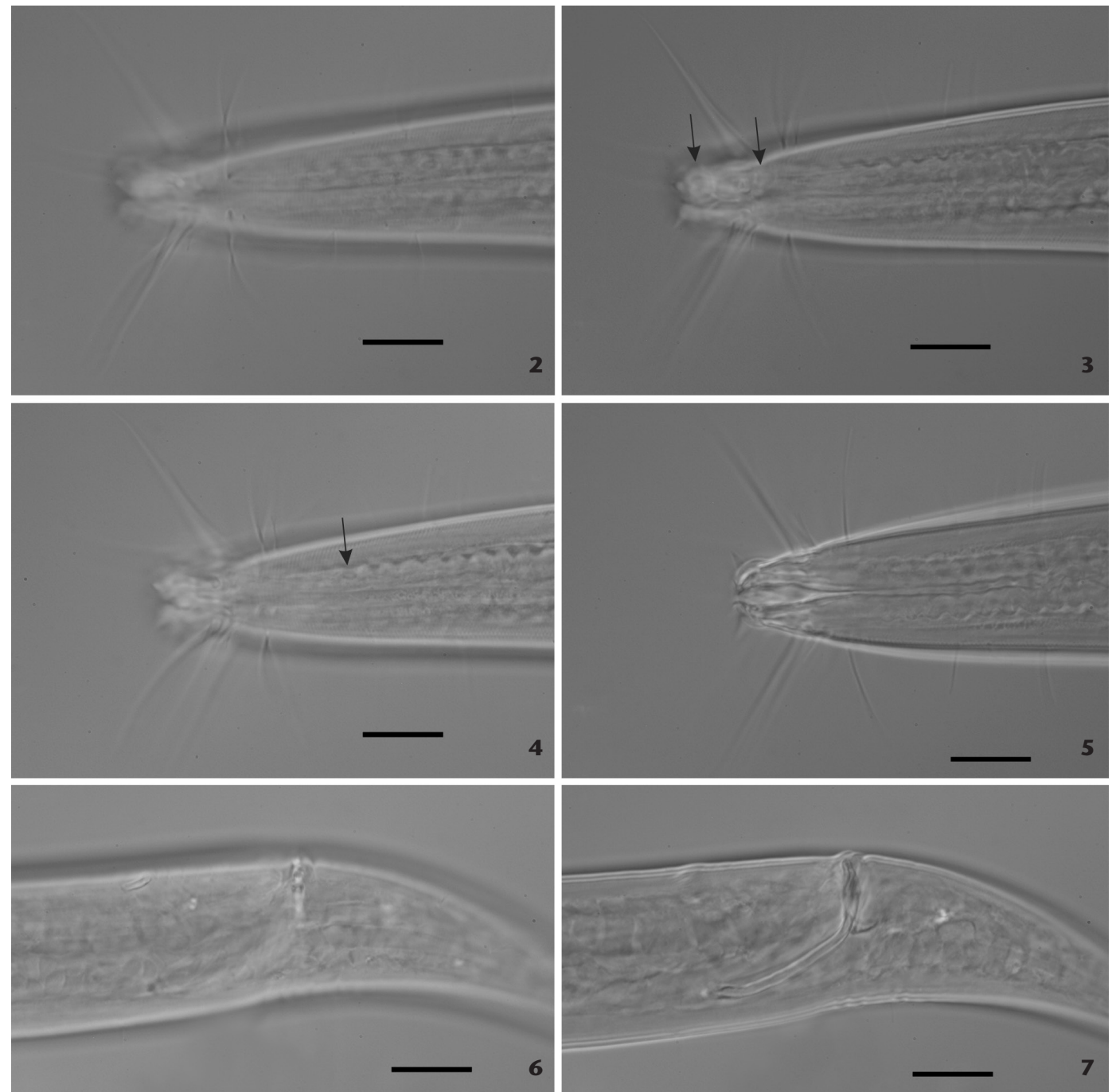

Figures 2-7. Holotype of Trileptium ribeirensis sp. nov.: anterior region showing setae (2), cephalic ring and amphid (3), orthometaneme (4) and teeth and jaws (5); posterior region with emphasis on the supplement (6) and the spicules and gubernaculum (7). Scale bars $=20 \mu \mathrm{m}$.

and velum, ventrally curved $(56 \mu \mathrm{m})$. Laminar gubernaculum $(13 \mu \mathrm{m})$ with a dorsal-caudal apophysis $(6 \mu \mathrm{m})$. Presence of a sclerotized and tubular pre-cloacal supplement $(8 \mu \mathrm{m}) 38 \mu \mathrm{m}$ from the cloaca. Conical tail $(189 \mu \mathrm{m})$ tapering at the terminal portion, with irregularly distributed setae (5 to $8 \mu \mathrm{m})$. No caudal glands were observed. Presence of spinneret $(4 \mu \mathrm{m})$.

Allotype: Similar to the description of the male, except for the sub cephalic setae, which are present only in males. The sub cephalic setae is a sexual dimorphism in this species. Females had a didelphic reproductive system with opposite reflected ovaries (anterior $1984 \mu \mathrm{m}$, and posterior $1990 \mu \mathrm{m}$ ) left to the intestine. The vulva is located $2700 \mu \mathrm{m}$ from the anterior end, equivalent to $63 \%$ of the body length. Only non-gravid females were observed.
Etymology. The species' name honors the site where the animals were collected. This is the first description of a new species of Nematode for Ribeira Beach, Salvador, Bahia, Brazil.

\section{DISCUSSION}

The presence of sub-cephalic setae only in males indicates a type of sexual dimorphism. This dimorphism is constant in the genus, being also present in T. australis, T. longisetosum, T. otti and T. salvadoriense.

Trileptium ribeirensis sp. nov. was characterized as a new species based on the fact that males have a slightly annulated cuticle, a buccal cavity with three isometric teeth on the same level and across the transverse mandibular bar, a supplement 


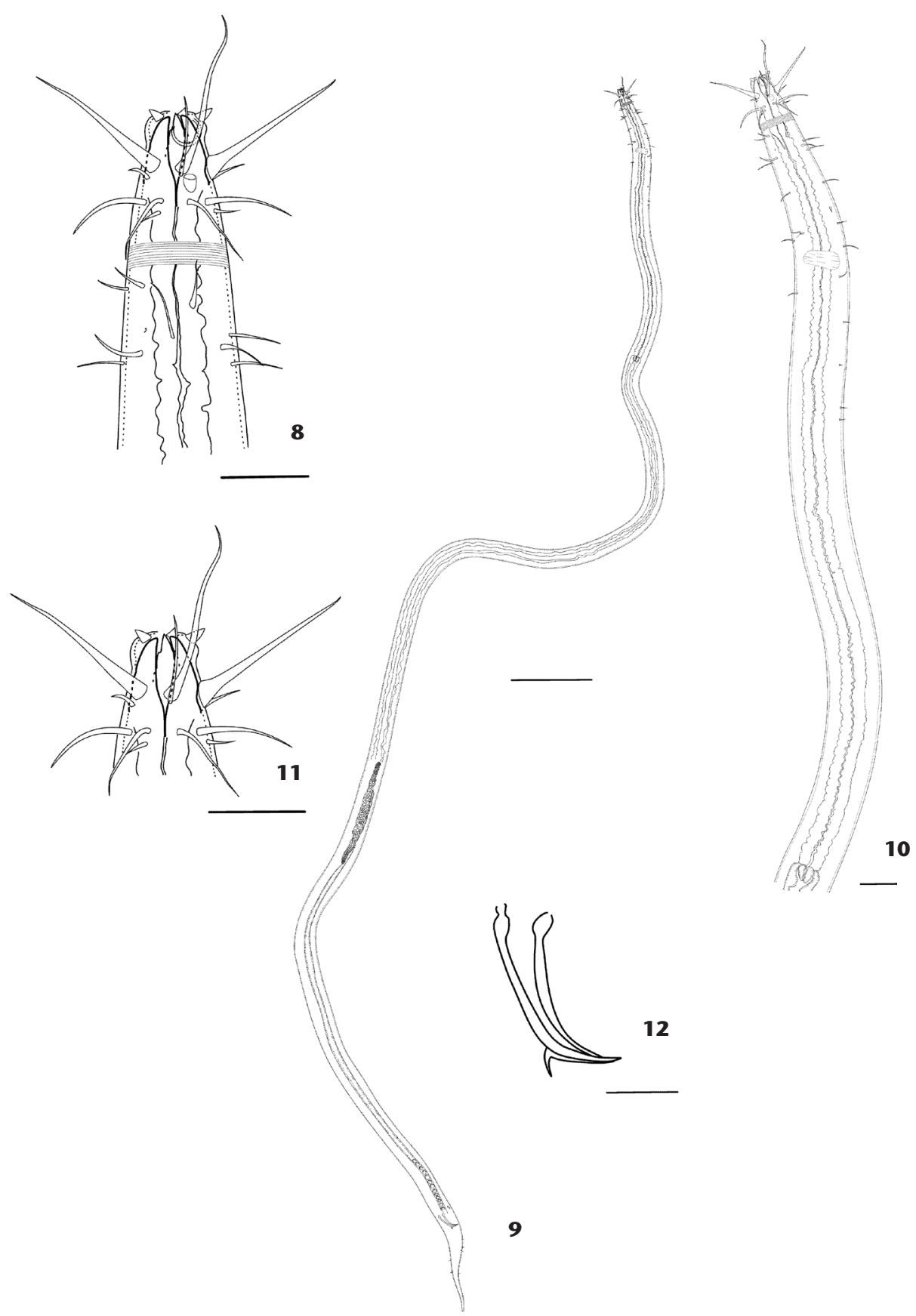

Figures 8-12. Holotype of Trileptium ribeirensis sp. nov.: (8) anterior region showing cephalic ring, amphid and cuticle; (9) total body; (10) body region with pharynx, nerve ring, somatic seta and cardia; (11) anterior region emphasizing setae and teeth; (12) spicules and gubernaculum. Scale bars: $8,10,11=50 \mu \mathrm{m}, 9=200 \mu \mathrm{m}, 12=20 \mu \mathrm{m}$.

and a gubernaculum with dorsal-caudal apophysis that does not loop over spicules (Table 2).

Following GERLACH (1952), T. subterraneum has a gubernaculum with dorsal-caudal apophysis, similar to the new species.
However, T. subterraneum does not have an annulated cuticle, and its buccal cavity contains a single onchium. Differently, $T$. ribeirensis sp. nov. has a slightly annulated cuticle and three isometric teeth. 


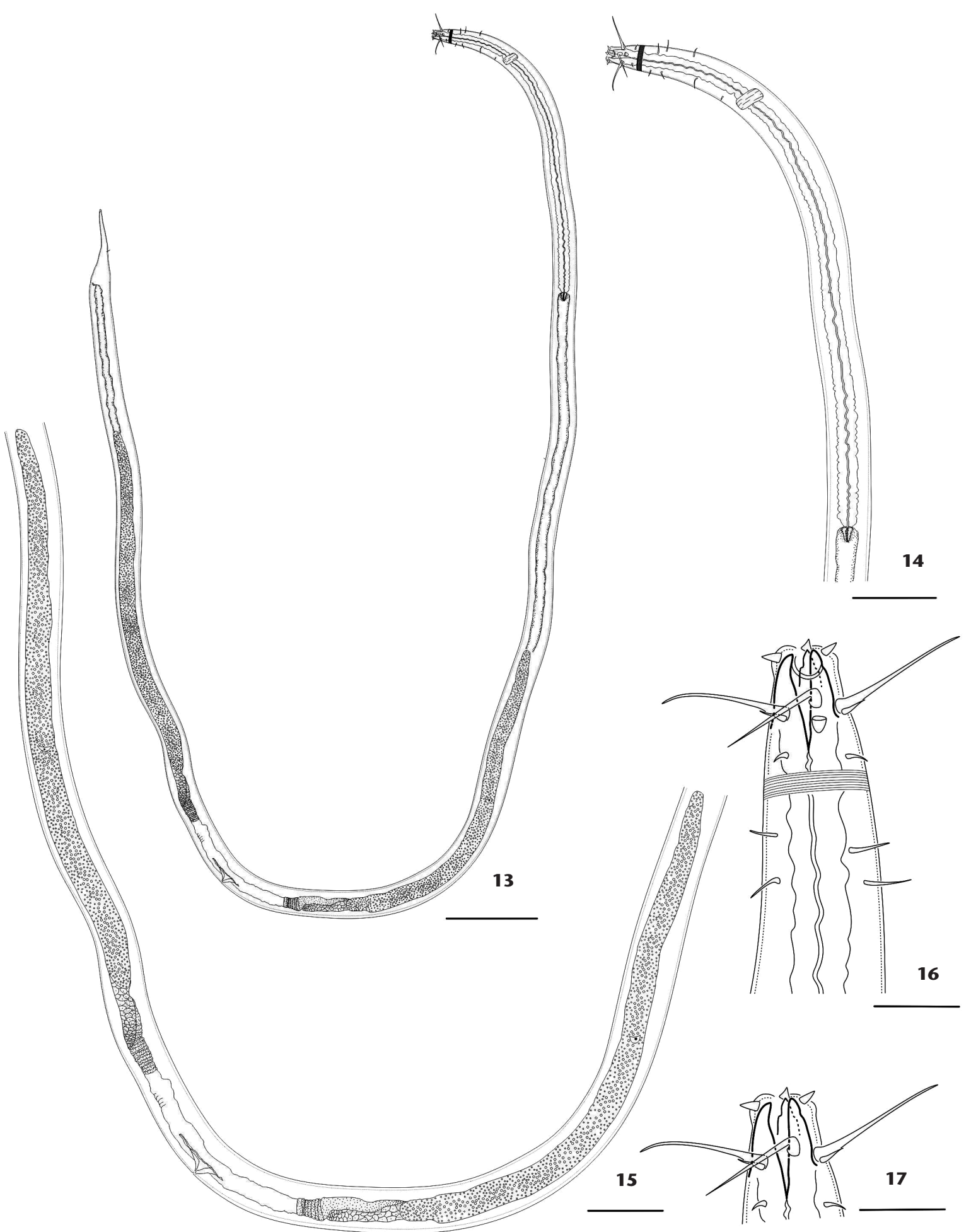

Figures 13-17. Allotype of Trileptium ribeirensis sp. nov.: (13) total body; (14) anterior region with pharynx, nerve ring, somatic seta and cardia; (15) body region showing the vulva and ovaries; (16-17) anterior region emphasizing the cephalic ring and amphid: (16), teeth and jaws (17). Scale bars: $13=200 \mu \mathrm{m}, 14,15=100 \mu \mathrm{m}, 16,17=50 \mu \mathrm{m}$. 


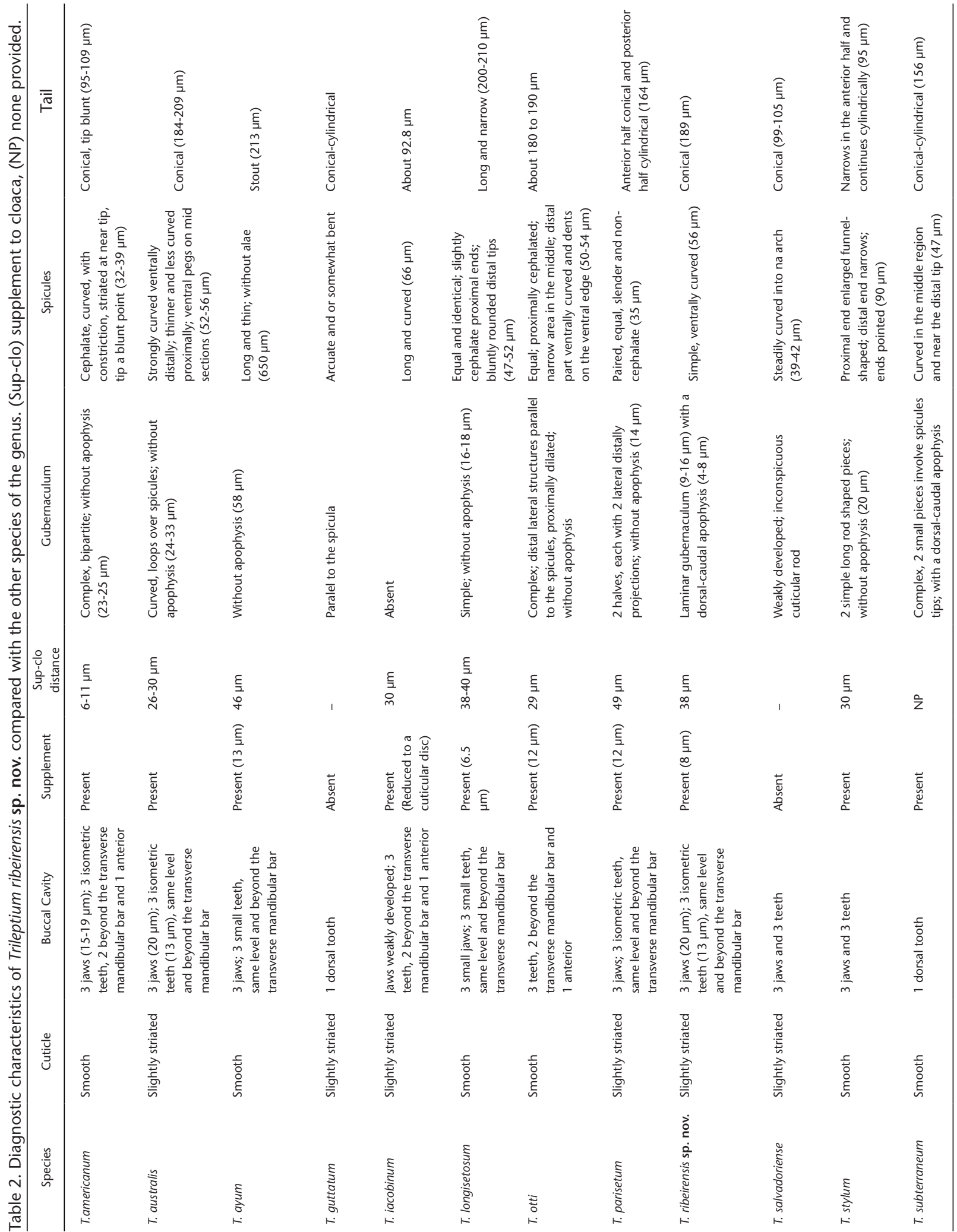


Trileptium ribeirensis sp. nov. differed from T. guttatum in the supplement and spinneret, which were absent in the species described by Совв (1920), and the gubernaculum, which, according to NichOlas (2007), had no apophysis in T. guttatum. Compared with $T$. parisetum, both species have spinnerets and pre-cloacal supplements, but their gubernaculums have only one piece and lack lateral projections at their tip, though they present apophysis. The supplement of T. ribeirensis sp. nov. is smaller than that described by WARWICK \& PLATT (1973), averaging 6 to $9 \mu \mathrm{m}$ in length, while in T. parisetum it has $12 \mu \mathrm{m}$.

The main differences between $T$. salvadoriense and $T$. ribeirensis sp. nov. were the presence of the supplement and the morphology of the gubernaculums, simple- structured in $T$. salvadoriense. Besides, the spicules of T. salvadoriense were slightly smaller than those of the new species, ranging from 39 to 42 $\mu \mathrm{m}$ (GERLaCH 1955), while in T. ribeirensis sp. nov. specimens the shortest spicules measured $55 \mu \mathrm{m}$ and the longest $62 \mu \mathrm{m}$.

When comparing T. ribeirensis sp. nov. with T. stylum, the cuticle of T. stylum is smooth. Furthermore, the buccal cavity $T$. stylum' is simple, small and the structures are difficult to view (Gerlach 1956). The spicules are large (90 $\mu \mathrm{m}$ length), and the gubernaculum is simple. The buccal cavity of T. ribeirensis sp. nov. has teeth and jaws. The largest spicules measured $61 \mu \mathrm{m}$ and the gubernaculum had an apophysis.

Trileptium iacobinum is different from the new species and the congeners in having no gubernaculum. The males have a cuticular plate, just above the anus, which WIESER (1959) believed to be a transformed tubular pre-cloacal supplement.

Unlike T. ribeirensis sp. nov. and the other species of the genus, T. americanum has three similar post-cloacal supplements near the tail tip (Keppner 1987). As in T. ribeirensis sp. nov., it has three teeth and three jaws, but in different positions, not across the mandibular transverse bar. In the new species, teeth and jaws are at the same level and lie beyond the mandibular bar. Its spicules are smaller ( 32 to $39 \mu \mathrm{m}$ ) than in the species under study, with a constriction at approximately one third of the distance from the proximal region, and with a striated area on the ventral side of the distal region. In addition, the gubernaculum has no apophysis.

The measurements of the spicules of $T$. otti are similar to those of T. ribeirensis sp. nov. However, their morphology is more complex, with a median curvature and a serrated distal tip (JENSEN \& GERLACH 1976). Furthermore, the shape of the gubernaculum is different, as is the size of the pre-cloacal supplement measuring $12 \mu \mathrm{m}$ in T. otti and ranging from 6 to $9 \mu \mathrm{m}$ in T. ribeirensis sp. nov. Another difference is the distance of the supplement to the cloaca, which is $29 \mu \mathrm{m}$ in T. otti and ranges from 37 to 48 $\mu \mathrm{m}$ in the new species.

The spicules of T. longisetosum and T. ribeirensis sp. nov. are similar but in the former species they are slightly smaller (47 $\mu \mathrm{m}$ and $52 \mu \mathrm{m})$, and the gubernaculum is simpler, without an apophysis, according IngLis (1966). Trileptium ayum, as described by Inglis (1964), differs from all Trileptium and T. ribeirensis sp. nov. species in the length of its slender spicules and gubernacula, $650 \mu \mathrm{m}$ and $58 \mu \mathrm{m}$, respectively. Finally, T. australis has peculiar spicules, having median expansions, and the curved gubernaculum contours the spicules (NichOLAs 2007).

According to the Nicholas (2007), the first step in the identification of Trileptium is to group them based on type of cuticle (smooth or annulated) and presence of gubernaculum. The cuticle of T. ribeirensis sp. nov. showed a similar pattern to that found in T. guttatum, T. parisetum and T. salvadoriense (i.e., not completely smooth), and all those species have a gubernaculum. Therefore, we suggested an amendment in step 1 to modify the proposal by NichOLAs (2007).

Below is a dichotomous key, proposed in this work, modified from Nicholas (2007). The main changes were as follows: (1) in step 1, we inserted the variation annulated cuticle absent in the original key; and (2) we included T. ribeirensis sp. nov. as a species of the genus.

\section{Taxonomic key to male Trileptium (modified from NichOLAS 2007)}

1. Cuticle annulated, gubernaculum absent T. iacobinum Wieser, 1959

$1^{\prime}$. Cuticle smooth or annulated, gubernaculum present ........2

2. Buccal cavity with a single forwardly-directed dorsal onchium. ...3

2 '. Buccal cavity with dorsal and two sub-ventral onchia .......4

3. Supplement absent, gubernaculum without apophysis......... T. guttatum (Cobb, 1920)

3'. Supplement present, gubernaculum with a dorso-caudal apophysis ........................ T. subterraneum (Gerlach, 1952)

4. Supplement absent ................. T. salvadoriense Gerlach, 1955

4'. Supplement present .......................................................... 5

5. Dorsal onchium does not reach the mandibular transverse bar, sub-ventral onchia extend beyond bar......................... 6

5'. Dorsal and subventral onchia at same level, extend beyond mandibular bar ......................................................... 7

6. Pre-cloacal supplement close to cloaca $(6-11 \mu \mathrm{m})$ T. americanum (Keppner, 1987)

6'. Pre-cloacal supplement not close to cloaca $(29 \mu \mathrm{m})$.............. T. otti Jensen \& Gerlach, 1976

7. Spicules shallow arcs, gubernaculum does not loop over spicules .

\section{.8}

7 '. Spicules strongly curved distally, gubernaculum with ventral peg, loops over both spicules......T. australis Nicholas, 2007

8. Gubernaculum with dorso-caudal apophysis. T. ribeirensis $\mathbf{s p}$. nov.

8'. Gubernaculum without apophysis . .9

9. Tail long and thin, 5 times body width at cloaca................... T. longisetosum Inglis, 1966 
$9^{\prime}$. Tail 4 times or less than body width at cloaca

10. Gubernacula terminate in small plates each, with two lateral projections T. parisetum Warwick \& Platt, 1973

$10^{\prime}$. Spicules cylindrical tapering to point, gubernaculum reduced to knob obscuring spicule tip.....

T. stylum Gerlach, 1956

10". Gubernaculum without terminal projections; does not obscure spicule tip T. ayum Inglis, 1964

\section{ACKNOWLEDGMENTS}

We would like to thank Nic Smol for providing assistance in the identification of the animals; to André M. Esteves and Facelúcia B.C. Souza for editing the manuscript; to Vlaams Instituut Voor to Zee for sending the requested literature; to financial aid through Coordenação de Aperfeiçoamento de Pessoal de Nível Superior (CAPES) and Fundação de Amparo à Pesquisa do Estado da Bahia (FAPESB). We would also like to thank the Programa de Pós-Graduação em Diversidade Animal (PPGDA), the Universidade Federal do Rio de Janeiro, Petrobras, and the Laboratório de Meiofauna of the Universidade Federal de Pernambuco (Veronica Fonsêca-Genevois and André M. Esteves). This manuscript was translated into English by American Journal Experts (AJE).

This work is part of the "Brazilian Marine Biodiversity: Development of Marine Nematoda Taxonomy " Project, coordinated by Orane F.S. Alves. This project is part of the "Marine Environmental Monitoring Network" Program, in partnership with the Universidade Federal de Pernambuco and the Universidade Federal do Pará, and has funding from Petrobras (project 0050.0023462.06.4).

\section{LITERATURE CITED}

Bik HM, Lambshead JD, Thomas, WK, Lunt DH (2010) Moving towards a complete molecular framewok of the Nematoda: a focus on the Enoplida and early-branching clades. Evolutionary Biology 10(353): 1-14.

Совв NA (1917) Notes on nemas. Contribution Science of Nematology 5: 11.

Совв NA (1920) One hundred new nemas (type species of 100 new genera). Contribution to Science of Nematolology 9: 217-343.

Совв NA (1933) New nemic genera and species, with taxonomic notes. The Journal of Parasitology 20(2): 81-94.

De GRISSE AT (1969) Redescription ou modification de quelques techniques utilisés dans l'étude des nématodes phytoparasitaires. Meded. Rijksfakulteit Landbouwwetenschappen 34: 251-369.

Gerlach SA (1952) Nematoden aus dem Küstengrundwasser. Akademie der Wissenschaften und der Literatur in Mainz 6: 315-372.
Gerlach SA (1955) Zur Kenntnis der freilebenden marinen Nematoden von San Salvador. Zeitschrift für Wissenschaftliche Zoologie 158: 249-303.

GerLach SA (1956) Brasilianische Meeres-Nematoden I. Boletim do Instituto Oceanográfico 5: 3-69.

Greenslade P, Nicholas WL (1991) Some Thoracostomopsidae (Nematoda: Enoplida) from Australia, including Descriptions of Two New Genera and Diagnostic Keys. Invertebrate Taxonomy 4: 1031-1052.

INGLIS WG (1964) The marine Enoplida (Nematoda): a comparative study of the head. Bulletin of the British Museum (Natural History) Zoology 11: 265-375.

IngLIS WG (1966) Marine nematodes from Durban, South Africa. Bulletin of the British Museum (Natural History) Zoology 14: $75-106$

Jensen P, Gerlach SA (1976) Three New Marine Nematodes from Bermuda. Veröff Inst Meeresforsch Bremerh 16: 31-44.

KeppNer EJ (1987) Five new species of free-living marine nematodes (Nematoda: Enoplida) from a northwest Florida, U.S.A. estuary. Transactions of the American Microscopical Society 106: 333-347.

Lo Russo V, Villares G, Martelli A, Pastor de Ward CT, Harguinteguy C (2013) New species of Epacanthion (Nematoda: Thoracostomopsidae) from Patagonia coast, Rio Negro and Chubut, Argentina. Journal of the Marine Biological Association of the United Kingdom 93(4): 925-934.

LORENZEN S (1981) Entwurf eines phylogenetischen Systems der freilebenden Nematoden. Veröffentlichungen des Instituts für Meeresforschung in Bremerhaven, Supplement 7: 1-472.

LORENZEN S (1994) The phylogenetic sistematics of freeliving nematodes. London, The Ray Society, 383p.

Nicholas WL (2007) A new species of Trileptium (Nematoda, Thoracostomopsidae) from a sandy beach in southeastern Australia, with a key to species and observations on geographical distribution. New Zealand Journal of Marine and Freshwater Research 41: 335-344.

Platt HM, WarWick RM (1983) Free-living Marine Nematodes Part 1 - British Enoplids. Cambridge, Cambridge University Press, 307p.

Silva IR, Flexor MHO, Nascimento S, Souza-Filho JR, Santana-Neto SP, Alves JE (2010) Subsídios para a Gestão e o Aproveitamento do Espaço Costeiro na Península de Itapagipe, Salvador, Bahia. Revista da Gestão Costeira Integrada 10(4): 505-519.

Smol N, Coomans A (2006) Ordem Enoplida, p. 497-573. In: Eyualem-Abebe, Traunspurger W, Andrássy I (Eds.). Freshwater Nematodes: Ecology and Taxonomy. Wallingford, CABI Publishing.

Venekey V, Fonseca-Genevois VG, Santos PJP (2010) Biodiversity of free-living marine nematodes on the coast of Brazil: a review. Zootaxa 2568: 39-66.

VILAs BoAs GS, BitTencourt ACSP (1992) Variação da energia e sua repercussão nas características composicionais e texturais em sedimentos praiais atuais: exemplo da costa leste da Baía de 
Todos os Santos, Bahia, Brasil. Revista Brasileira de Geociências 22(3): 311-320.

Warwick RM, Platt HM (1973) New and little known marine nematodes from a Scottish sandy beach. Cahiers de Biologie

Submitted: 14 April 2015

Received in revised form: 17 November 2015

Accepted: 2 December 2015

Editorial responsibility: Paulo da Cunha Lana

Author contributions: Found the new species and wrote the paper: ACVB. Co-guided the Master's project and supported the description: MCS. Coordinated and guided the Master's project and collected the samples: OFSA. Reviewed the paper and made the drawings: FJVC. Made the pictures and supported the corrections: EPPJ.

Competing interests: The authors have declared that no competing interests exist.
Marine 14: 135-138.

Wieser W (1959) Free-living nematodes and other small invertebrates of Puget Sound beaches. Seattle, University of Washington, 179p. 